Journal of IMAB

ISSN: 1312-773X

https://www.journal-imab-bg.org

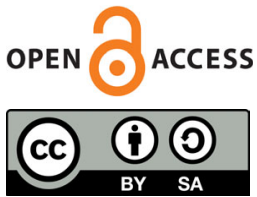

Journal of IMAB - Annual Proceeding (Scientific Papers). 2018 Oct-Dec;24(4)

Review article

\section{ASPECTS OF THE NUTRITIONAL STATUS OF CHILDREN WITH ADOLESCENT IDIOPATHIC SCOLIOSIS. LITERATURE REVIEW.}

\author{
Dimitar B. Marinov ${ }^{1}$, Darina N. Hristova ${ }^{2}$, Teodora T. Dimitrova ${ }^{1}$ \\ 1) Department of Hygiene and Epidemiology, Faculty of Public Health, Medical \\ University of Varna \\ 2) Department of Preclinical and Clinical Sciences, Faculty of Pharmacy, \\ Medical University of Varna, Bulgaria.
}

\section{SUMMARY}

AIS is a very common condition amongst adolescents in Bulgaria, and it has no effective prophylaxis, because of its unknown etiology. Few factors possibly play a role in the etiopathogenesis, one of which is the lifestyle, and more specifically the levels of some nutrients, and the anthropometrics. These aspects can be described as parts of the nutritional status of the patients with AIS. Numerous studies find a high incidence of vit. D deficiency amongst AIS patients(75-97\%). Significantly higher compared to control groups. Few studies also find a negative correlation between the progression of the disease and bone density, and calcium levels respectively. Majority of the studies show that, when compared with a control population, scoliotic patients had a significantly lower mean body weight, lower BMI, lower fat and lean mass. The low lean body mass is suggested by some studies as the main contributor. One recent cohort study shows that the low anthropometrical indicators appear first, suggesting their possible role in the etiopathogenesis.

Keywords: adolescent idiopathic scoliosis, anthropometrics, vitamin-D deficiency, low body mass

\section{BACKGROUND}

Adolescent idiopathic scoliosis (AIS) is one of the most common conditions amongst adolescents in Bulgaria, alongside obesity, myopia and asthma, and affects 4-5\% of all adolescents. Milder cases, with Cobb's angle below 10 degrees are even more common, and some studies show that they might be less benign than previously thought. [1] Teenagers with small curves may not present to secondary care but are nonetheless reporting increased pain, more days off school, and avoidance of activities. The condition is more prevalent in females, especially the severe cases. Etiology is multifactorial, and the exact cause remains unknown. Six groups of factors are proposed to have a role - genetics, hormonal, abnormalities in the nervous system, abnormal skeletal growth, biomechanical and lifestyle factors. Lifestyle factors include nutrition, diet, calcium and vitamin D intake, and physical activity. The effect of those lifestyle factors can be evaluated using aspects of the nutritional status of these children.

This literature review will discuss some aspects of the nutritional status of children with AIS, affected by lifestyle factors with a possible role in the condition, like biochemical levels of some nutrients and anthropometrical indicators.

\section{REVIEW RESULTS}

Biochemical levels of some nutrients

Numerous studies show low levels of vit. D amongst patients with AIS. Balioglu et al. [2] performed the retrospective study in Istanbul, Turkey and compared 229 AIS patients with 389 age-matched controls and found out that the patients with AIS had significantly lower vit D levels. Vit. D levels correlated positively with Ca levels and negatively with Cobb's angle, indicative of a possible role of vit.D in the etiopathogenesis of AIS. The study suggested that patients with AIS should be monitored for vit.D deficiency/insufficiency.

Batista et al.[3] found that $91 \%$ of tested AIS patients showed low vit.D levels, compared to $63 \%$ of the control group, while also the average levels were lower in the AIS group - $18.8 \mathrm{ng} / \mathrm{mL}$, compared to $27 \mathrm{ng} / \mathrm{mL}$ in control group.

Mayes et al. [4] and Ricardo et al. [5] also found that AIS patients are deficient in vit.D. Mayes et al. studied 217 scoliotic patients (mostly AIS) with a mean age of $13.6 \pm 3.6$ years in Cincinnati, USA. They had vitamin D levels drawn a mean of $38.7 \pm 20.6$. Nearly $75 \%$ of the 
study population $(n=162)$ demonstrated D25 values below normal. In the study of Ricardo et al. almost all of the AIS patients (97\%) had lower 25-OHD levels than expected. However, no relationship was observed between vitamin D levels and the Cobb angle. The study was performed in Sao Paolo, Brazil.

Studies show that low calcium intake aggravates the consequences of vitamin D deficiency [6]. Sun et al. [7] identified osteopenia as a risk factor for curve progression in patients with AIS. They studied sixty-eight AIS patients. There were 17 girls $(25 \%)$ in group A and 51 girls (75\%) in group B, respectively. The girls in group A had a significantly larger initial Cobb angle (32.3 \pm 6.6 vs $29.1 \pm 5.3$ degrees) and significantly lower bone mass density of lumbar spine from L2 to L4 value $(0.80 \pm 0.11$ vs $0.88 \pm 0.12 \mathrm{~g} / \mathrm{cm})$.

Other researchers have linked inadequate calcium intake with osteopenia in AIS patients in an Asian population. Lee et al. [8, 9] found that the bone mass of AIS patients was on average $6.5 \%$ lower than controls across the ages.Multivariate analysis showed that AIS in girls was associated with lower bone mass and that both calcium intake and physical activity were independent predictors of bone mass in AIS.

Chlebna-Sokol et al. [10] found in a study of 74 children in Poland with skeletal abnormalities including scoliosis, all subjects had significantly low vit.D intake, and the majority also had a calcium deficiency. In the same group, 14/74 subjects had either osteopenia or osteoporosis.

From this information, we can deduce that vit. D and calcium deficiency are extremely common amongst patients with AIS and calcium can further aggravate the consequences by leading to osteopenia, which is likely one of the factors contributing to the progression of AIS. Most of the studies state that considering the small number of studies suggesting a correlation between 25-OHD and AIS, further studies are needed to support this hypothesis and to find the reasons behind this variation.

\section{Anthropometrical indicators}

When describing different anthropometrical indicators and body composition parameters of adolescents with AIS, the majority of the studies show that, when compared with a control population, scoliotic patients had a significantly lower mean body weight, lower Body Mass Index(BMI), lower fat and lean mass [13, 14, 15, 16, 18].

Grivas et al. [11] studied 5953 adolescents and found out that relatively lower BMIs are statistically associated with a greater number of severe truncal asymmetries(TAs) in the thoracolumbar and lumbar re- gions, than with relatively higher BMIs in both girls and boys. The relative frequency of severe TAs is significantly higher in girls than boys.

Zheng et al. [12]included 1,202 patients with AIS and an age- and gender-matched cohort. The underweight cases had the highest prevalence of AIS and significantly higher Cobb angle compared with the other three BMI subgroups. The patients with AIS had lower body weight, body fat mass, the percentage of body fat, and fat-free mass compared with healthy controls.

Durmala et al. [13] studied 303 children, aged 14 and found that almost one-third of children with IS are underweight, while obesity is rather a sporadic feature.

Serbescu et al. [14] studied 252 children in Romania, observing a high incidence of scoliosis amongst them $(16,6 \%)$. Girls presenting scoliosis had a specific somatic morphologic type when compared to a normal population - lower BMI, body fat and body mass.

Barrios et al. [15] found out that girls with AIS showed a progressive decrease of the BMI as the age increased. The study included 52 AIS girls (mean age: 13.9 years) with an average scoliotic curve of $27^{\circ} \mathrm{Cobb}$ (range: 20-58). The control group consisted of 92 girls without spine deformity, matched in age (mean: 13.8 years). Compared with the control population, scoliotic girls had a significantly lower mean weight $(51.4 \pm 10.2 \mathrm{~kg}$ vs. 54.7 $\pm 8.1 \mathrm{~kg} ; \mathrm{P}<0,05)$, and lower BMI $(20.1 \pm 3.4$ vs. $21.4 \pm$ $2.4 ; \mathrm{P}<0.001)$.

Ramirez et al. [16] also concluded that there is a real alteration of body composition in AIS. The BMI, FFMI and FMI are lower than in the general population in the series under study.

However, Matusik et al. [15] observed, in very severe cases of AIS, lower lean but higher fat mass. They acknowledge however that the excessive gain of adipose tissue might have occurred during the progression of the spinal deformity.

Clark et al. [18] performed the first populationbased prospective study on the subject of 5299 children without scoliosis at the age of 10 and at the age of 15 years $312(5.9 \%)$ had it developed. The study observed a negative association between BMI/body weight at age 10 years and incidence of scoliosis at age 15 years, with a $20 \%$ reduced risk of scoliosis per SD increase in BMI (Table 1). This association with BMI/body weight reflects associations with both fat mass and lean mass. This study confirms previous studies and also shows that it is not scoliosis that induces low body weight, for example through concerns about body image, but that the altered anthropometrical indicators appear first, and maybe body composition has a role in the etiopathogenesis of AIS. 
Table 1. Prospective analyses of the association between measures of length, weight, and body composition at age 10 years with the presence of scoliosis over 6 degrees at age 15 years, by Clark et al. [18]

\begin{tabular}{|c|c|c|c|}
\hline Measures at age of 10 & $\begin{array}{c}\text { Without } \\
\text { scoliosis at age } \\
15 \text { years mean } \\
\text { SD }(n=4371)\end{array}$ & $\begin{array}{l}\text { With scoliosis at } \\
\text { age } 15 \text { years mean } \\
\text { SD }(n=266)\end{array}$ & $\mathrm{p}$ for difference \\
\hline \multicolumn{4}{|l|}{ Length (cm) } \\
\hline Standing height & 139.6 & 140.1 & $\mathrm{p}=0.295$ \\
\hline Sitting height & $73.1 \pm 4.2$ & $73.3 \pm 3.4$ & $\mathrm{p}=0.590$ \\
\hline Calculated leg length & $66.3 \pm 4.7$ & $66.8 \pm 4.0$ & $\mathrm{p}=0.106$ \\
\hline Humeral length & $25 \pm 1.5$ & $25.1 \pm 1.6$ & $\mathrm{p}=0.336$ \\
\hline \multicolumn{4}{|l|}{ Weight } \\
\hline $\mathrm{BMI}\left(\mathrm{kg} / \mathrm{m}^{2}\right)$ & $17.6 \pm 2.8$ & $17.2 \pm 2.9$ & $p=0.006$ \\
\hline Body weight (kg) & $34.6 \pm 7.3$ & $33.8 \pm 7.2$ & $\mathrm{p}=0.093$ \\
\hline Total body fat mass (kg) & $8.4 \pm 5.0$ & $8.3 \pm 4.9$ & $\mathrm{p}=0.622$ \\
\hline Total body lean mass $(\mathrm{kg})$ & $24.5 \pm 3.2$ & $23.9 \pm 3.3$ & $p=0.002$ \\
\hline
\end{tabular}

\section{CONCLUSION}

There is strong evidence about tendencies in the nutritional status of children with AIS. Mainly regarding the levels of vit. D, calcium and body composition. It is interesting that some studies show that these tendencies might appear prior to the condition, while other also find a positive correlation between them and the severity of the AIS, thus they might have a role in the etiopathogenesis of the disease, as well as in its management. However, more research is needed to evaluate the exact relation and effect of different lifestyle factors on the nutritional status of children with AIS.

\section{REFERENCES:}

1. Clark EM, Tobias JH, Fairbank J. The Impact of Small Spinal Curves in Adolescents Who Have Not Presented to Secondary Care: A Population-Based Cohort Study. Spine. 2016 May 15;41(10):E611-E617. [Crossref]

2. Balioglu MB, Aydin C, Kargin D, Albayrak A, Atici Y, Tas SK, et al. Vitamin-D measurement in patients with adolescent idiopathic scoliosis. $J$ Pediatr Orthop B. 2017 Jan;26(1):4852. [PubMed] [Crossref]

3. Batista R, Martins DE, Hayashi Li F, Lazaretti-Castro M, Puerta EB, Wajchenberg M. Association between vitamin D serum levels and adolescent idiopathic scoliosis. Scoliosis. 2014; 9(Suppl. 1):O45. [Crossref]

4. Mayes T, Anadio JM, Sturm PF. Prevalence of Vitamin D Deficiency in
Pediatric Patients with Scoliosis Preparing for Spinal Surgery. Spine Deform. 2017 Nov;5(6):369-373. [PubMed] [Crossref]

5. Silva RTE, Fernandes RJR, Ono AHA, Marcon RM, Cristante AF, Barros TEP Filho. Role of different hormones in the pathogenesis and severity of adolescent idiopathic scoliosis. Acta Ortop Bras. 2017 Jan-Feb; 25(1):15-17. [PubMed] [Crossref]

6. Lips P. Interaction between vitamin D and calcium. Scand J Clin Lab Invest Suppl. 2012;243:60-4. [PubMed] [Crossref]

7. Sun $X, W u T$, Liu Z, Zhu Z, Qian B, Zhu F, et al. Osteopenia predicts curve progression of adolescent idiopathic scoliosis in girls treated with brace treatment. J Pediatr Orthop.
2013 Jun;33(4):366-71 [PubMed] [Crossref]

8. Lee WT, Cheng JC, Cheung CS, Guo X. Inadequate calcium intake is a significant determinant on generalised osteopenia in Hong Kong Chinese adolescents with idiopathic scoliosis. Wei Sheng Yan Jiu. 2003 Nov;32(6): 568-72. [PubMed]

9. Lee WT, Cheung CS, Tse YK, Guo X, Qin L, Ho SC, et al. Generalized low bone mass of girls with adolescent idiopathic scoliosis is related to inadequate calcium intake and weight bearing physical activity in peripubertal period. Osteoporos Int. 2005 Sep;16(9):1024-35. [PubMed] [Crossref]

10. Chlebna-Sokol D, Blaszczyk A, Trafalska E, Grzybowski A. [Bone 
mineralization in children with skeletal system abnormalities in relation to dietary intake of some nutrients.] [in Polish] Przegl Lek. 2003; 60(Suppl.6): 60-4. [PubMed]

11. Grivas TB, Burwell RG, Mihas C, Vasiliadis ES, Triandaffylopoulos G, Kaspiris A. Relatively lower body mass index is associated with an excess of severe truncal asymmetry in healthy adolescents. Do body fat, leptin, hypothalamus and sympathetic nervous system influence truncal growth asymmetry? Scoliosis. 2009 Jun 40;4:13. [PubMed] [Crossref]

12.Zeng Y, Dang Y, Yang Y, Sun N, Wang T, Li H, et al. A Case-Control Study of Body Composition, Prevalence, and Curve Severity of the $\mathrm{Pa}$ tients With Adolescent Idiopathic Sco- liosis in the East Part of China. Spine Deform. 2017 Nov;5(6):374-380. [PubMed] [Crossref]

13. Durmala J, Sosnowska M, Sosnowski M. Nutritional status in idiopathic scoliosis. Scoliosis. 2012; 7(Suppl 1):O22. [PMC] [Crossref]

14. Serbescu C, Ianc D, Straciuc O, Carp G, Courteix D. Epidemiological study of scoliosis of Romanian school children. Science \& Sports. 22 (2007), 307-308. [Crossref]

15. Barrios C, Cortes S, PerezEncinas C, Escriva MD, Benet I, Burgos J, et al. Anthropometry and body composition profile of girls with nonsurgically treated adolescent idiopathic scoliosis. Spine (Phila Pa 1976). 2011 Aug 15;36(18):1470-7. [PubMed] [Crossref]
16. Ramírez M, Martínez-Llorens J, Sanchez JF, Bagó J, Molina A, Gea J, et al. Body composition in adolescent idiopathic scoliosis. Eur Spine J. 2013 Feb;22(2):324-9. [PubMed] [Crossref]

17. Matusik E, Durmala J, Matusik P. Association of Body Composition with Curve Severity in Children and Adolescents with Idiopathic Scoliosis (IS). Nutrients. 2016 Jan 28;8(2):71. [PubMed] [Crossref]

18. Clark EM, Taylor HJ, Harding I, Hutchinson J, Nelson I, Deanfield JE, et al. Association between components of body composition and scoliosis: a prospective cohort study reporting differences identifiable before the onset of scoliosis. J Bone Miner Res. 2014 Aug;29(8):1729-36. [PubMed] [Crossref]

Please cite this article as: Marinov DB, Hristova DN, Dimitrova TT. Aspects of the nutritional status of children with adolescent idiopathic scoliosis. Literature review. J of IMAB. 2018 Oct-Dec;24(4):2281-2284.

DOI: https://doi.org/10.5272/jimab.2018244.2281

Received: 14/06/2018; Published online: 13/11/2018

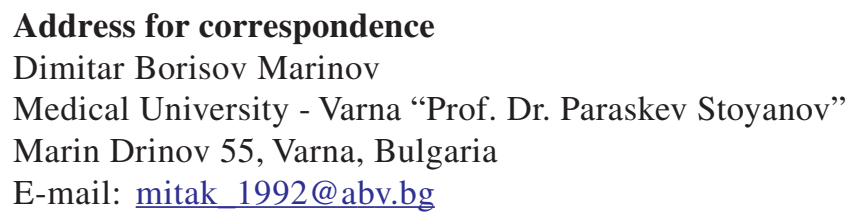

